\title{
Research on Application of rapid assessment of Load-bearing capacity of composite girder bridges based on displacement influence line
}

\author{
Pinde $\mathrm{Yu}{ }^{1,2, \mathrm{a}}$, Kun Cheng ${ }^{1,2, \mathrm{~b}}$, Hua $\mathrm{Li}^{1,2, \mathrm{c}}$ \\ 1.Henan Transporation Research Institute CO.,LTD, Zhengzhou China; \\ 2.Highway Bridge Safety Inspection and Reinforcement Technology Transportation Industry \\ Research and Development Center, Zhengzhou China; \\ aypd@hntri.com, ${ }^{\mathrm{b}} \mathrm{ck} @$ hntri.com, 'Lih@hntri.com
}

\begin{abstract}
Keywords: Composite girder bridge, influence line, Polynomial fitting, virtual load test ,Bridge evaluation.

Abstract. For rapid evaluation of composite girder beam bridges load-bearing capacity, to study the load-bearing capacity check computation method based on displacement influence line. First obtain measured displacement data of typical sections by the slow driving way, then calculate the measured generalized displacement influence line by using Polynomial fitting method.Based on the generalized displacement influence line for virtual load test, and then complete the rapid assessment of bridge carrying capacity. The results of engineering application on one $30 \mathrm{~m}$ simply supported $\mathrm{T}$ beam bridge show that : Compared with the load test method, this method results are reliable and convenient, and can be used for rapid assessment of load-bearing capacity of composite girder bridges.
\end{abstract}

\section{Introduction}

Composite girder bridges is widely used in our country because of its simple structure, easy construction, low cost, but such bridges during operations often has a variety of diseases, affecting traffic safety. Therefore, many methods have been proposed at home and abroad to evaluate the load-bearing capacity of the actual bridge structure. With the increase of the demand of the society, many scholars have carried out the research on the rapid evaluation method of load-bearing capacity of the bridge without interruption[1,2]. The evaluation method based on the influence line of bridge is one of the main research directions. Because of the boundary condition, geometry information and physical information of the bridge, the bridge influence line is used to study the problem of model updating[3], damage identification[4,5], bridge structure assessment and so on[6,7].

In this paper, based on the relevant research, for the composite girder bridges, the study of polynomial fitting to obtain the displacement of the line, is used to carry the test method. In order to validate the feasibility of the method, the test analysis is carried out by using the $30 \mathrm{~m} \mathrm{~T}$ bridge as the object.

\section{Displacement influence line test and Bridge Evaluation}

There are two ways to obtain the influence line of bridge by means of measuring method. One is static loading mode, which is to test the influence line of bridge by point static load test,and the other is the quasi-static test method[8,9], The dynamic displacement response to the actual bridge displacement can be calculated by the known calibration of the vehicle moving displacement response to the bridge.Dynamic displacement test inevitably contains the information of bridge vibration, especially for the simple supported boundary condition, which is more obvious, and increases with the increase of the speed of the vehicle. In this paper, we use the method of polynomial piecewise fitting to extract the influence line of bridge displacement[10].

For composite girder bridge, the influence line testing is generally performed by slow car lane test, each test will receive a set of influence lines, while the traditional load tests generally take two or more trains 
loaded, pressing a check calculation method to evaluate bridge when capacity, need to consider the combined effects of line testing working conditions. The main idea of the method is as follows:

(1) Test of the displacement influence line of each beam by quasi-static load test;

(2) The test load of the traditional static load test is applied on the measured influence line, and the calculated value of the static load test load is obtained. It must be noted that the traditional load test generally take 2 or more train loading, so fist it shoud calculate the beam displacement value by lane, then obtain the corresponding conditions of calculation value combined by load test.

(3) Compare the calculated values of the influence line of each beam with the theoretical calculation, Calculate the structure coefficient $\eta$, Obtain the checking coefficient $Z_{2}$ by conversion, And according to "highway bridge carrying capacity testing and evaluation procedures" (J21-2011 JTG/T) method to assess the carrying capacity of the bridge.

\section{Engineering application}

In order to verify the accuracy of the above method, this paper takes a $30 \mathrm{~m}$ span simply supported $\mathrm{T}$ beam as the test object, carries out the test of displacement influence line and the corresponding static load test. The total width of the test bridge is $12 \mathrm{~m}$, composed by horizontal 6 pieces of composite $\mathrm{T}$ beam, each precast $\mathrm{T}$ beam wide $2.1 \mathrm{~m}$, high $1.8 \mathrm{~m}$. As shown in figure 1 . The testing conditions are carried out in this paper:

Conditions 1: Displacement influence line test, Lane 1 from the sidewalk outside is $3.8 \mathrm{~m}$; single vehicle loading speed of $5 \mathrm{~km} / \mathrm{h}$ speed through the bridge, record data continuously;

Conditions 2: Displacement influence line test, Lane 2 from the sidewalk outside is $8.3 \mathrm{~m}$; single vehicle of $5 \mathrm{~km} / \mathrm{h}$ speed uniform speed through the bridge, record data continuously, repeat test 3 times;

Condition 3: Static load test under normal load conditions, 4 loading vehicles.

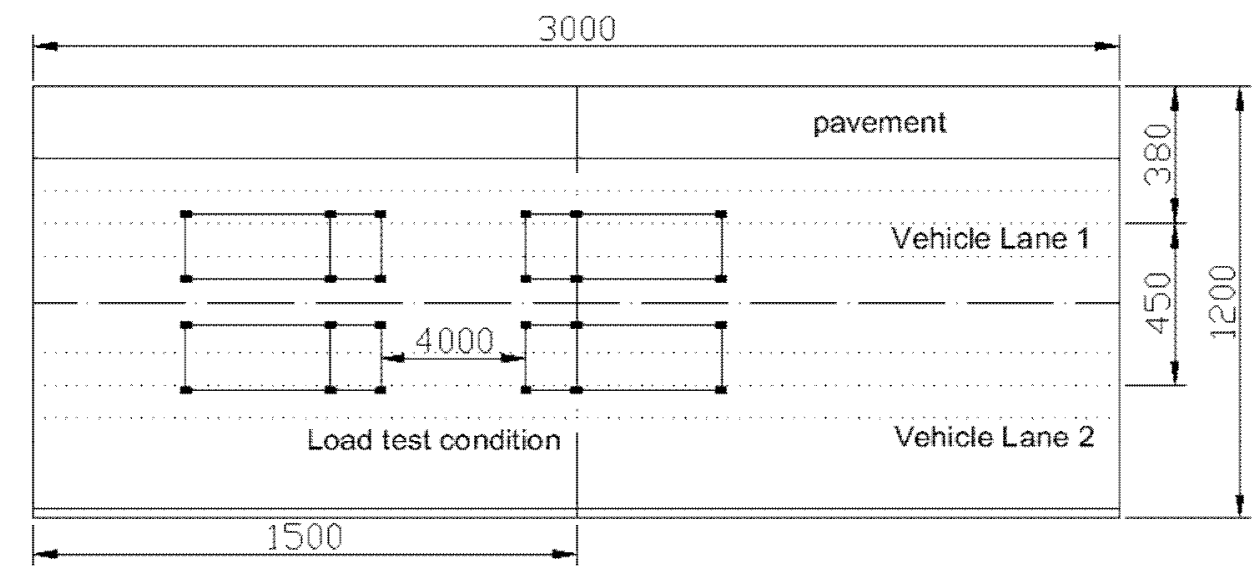

Vehicle Lane 1 Vehicle Lane 2
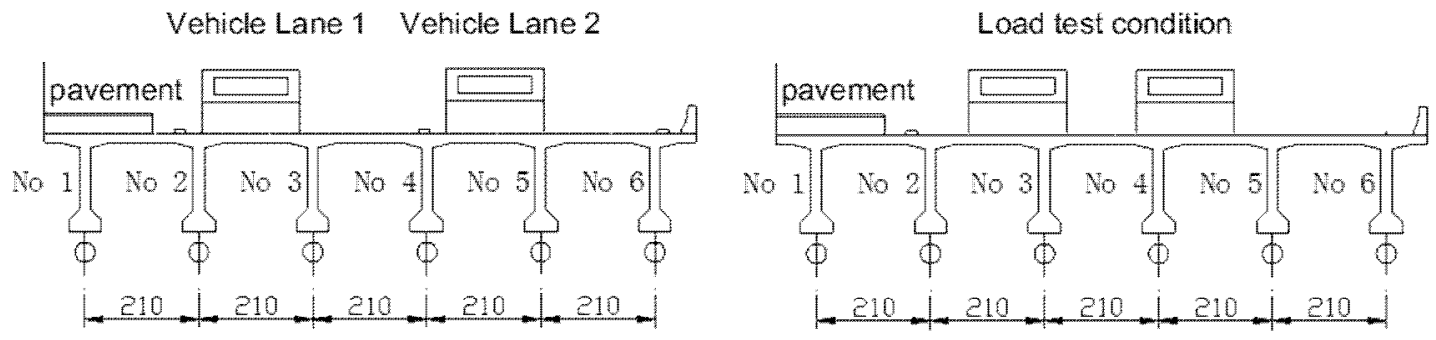

Fig1. Load Test load conditions 


\section{Test result}

As shown in Figure 2,It is the cross section displacement test data under the conditions 2, we can see: multiple tests, the beam displacement curve is basically the same, the maximum displacement value is basically the same.

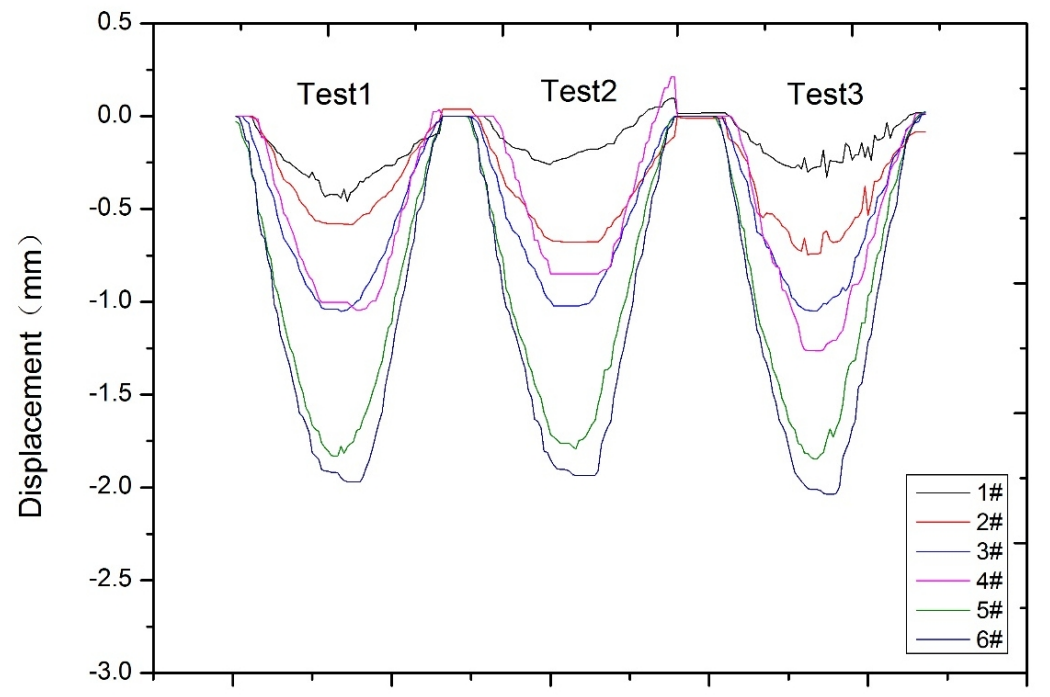

Fig 2. working conditions 2 sports car test displacement data

\section{Displacement influence line fitting result}

As shown in figure 1. The testing conditions are carried out in this paper: According to the influence line test data using the least square method to carry on the influence line fitting, the following steps are as follows:

(1) First of all, the data were processed by singular value discrimination, and the support was zero.

(2) According to the displacement test data, Test the weight of the vehicle, calculate the influence line of vertical displacement values.

(3) Influence line fitting. Considering the influence of various error factors in the actual test, this paper uses 4 times for polynomial fitting of the influence line, accounting for the influence line of bearing displacement for 0 , fitted by the formula (3), Where $\mathrm{Y}$ is the vertical displacement influence line values, $\mathrm{X}$ is the distance to the starting point of the beam.

$$
Y=A X+B X^{2}+C X^{3}+D X^{4}
$$

Condition 1, 2 beam influence line fitting results seen in Table 1, the fitting formula of the correlation coefficient is 0.99 or above, with a high degree of similarity.

Table1. Result of Influence line fitting

\begin{tabular}{|c|c|c|c|c|c|c|}
\hline \multirow{2}{*}{$\begin{array}{l}\text { Test } \\
\text { Conditions }\end{array}$} & \multirow{2}{*}{$\begin{array}{l}\text { No of } \\
\text { Beam }\end{array}$} & \multicolumn{4}{|c|}{ Fitting parameters } & \multirow{2}{*}{$\mathrm{R}$} \\
\hline & & A & B & $\mathrm{C}$ & $\mathrm{D}$ & \\
\hline \multirow{6}{*}{ Condition1 } & $1 \#$ & -0.17752 & -0.02768 & 0.00214 & -0.00003 & 0.99830 \\
\hline & 2\# & -0.11989 & -0.02622 & 0.00180 & -0.00003 & 0.99463 \\
\hline & 3\# & -0.10928 & -0.03102 & 0.00215 & -0.00003 & 0.99669 \\
\hline & $4 \#$ & -0.01527 & -0.03818 & 0.00238 & -0.00004 & 0.99635 \\
\hline & $5 \#$ & -0.07030 & -0.02598 & 0.00176 & -0.00003 & 0.99800 \\
\hline & 6\# & -0.02812 & -0.01944 & 0.00117 & -0.00002 & 0.99596 \\
\hline \multirow{6}{*}{ Condition 2} & $1 \#$ & -0.01636 & -0.01047 & 0.00072 & -0.00001 & 0.99478 \\
\hline & 2\# & -0.06130 & -0.01521 & 0.00108 & -0.00002 & 0.99875 \\
\hline & 3\# & -0.09475 & -0.02477 & 0.00173 & -0.00003 & 0.99683 \\
\hline & 4\# & -0.02651 & -0.03178 & 0.00185 & -0.00003 & 0.99963 \\
\hline & $5 \#$ & -0.20751 & -0.03687 & 0.00277 & -0.00004 & 0.99858 \\
\hline & 6\# & -0.24694 & -0.03426 & 0.00254 & -0.00004 & 0.99698 \\
\hline
\end{tabular}




\section{Displacement solution based on measured generalized influence line}

To verify the feasibility of the method, According to the method mentioned above, the deflection value of the measured influence line is compared with that of the load test, and the results are shown in table 2 .

Table 2 Comparison of the calculated value of the deflection and the load test data

\begin{tabular}{|c|c|c|c|c|c|}
\hline \multirow{2}{*}{ No. of Beam } & \multicolumn{3}{|c|}{ Displacement[mm] } & \multicolumn{2}{c|}{ Verification coefficient } \\
\cline { 2 - 6 } & Influence line & Load test & $\begin{array}{l}\text { Theoretical } \\
\text { calculation }\end{array}$ & Load test \\
\hline $1 \#$ & -2.69 & -2.87 & -8.39 & 0.32 & 0.34 \\
\hline $2 \#$ & -2.87 & -3.17 & -8.87 & 0.32 & 0.36 \\
\hline $3 \#$ & -3.52 & -3.97 & -9.21 & 0.38 & 0.43 \\
\hline $4 \#$ & -3.19 & -4.06 & -9.21 & 0.45 & 0.44 \\
\hline $5 \#$ & -4.24 & -4.05 & -8.87 & 0.48 & 0.45 \\
\hline $6 \#$ & -4.06 & -3.78 & -8.39 & 0.48 & 0.45 \\
\hline
\end{tabular}

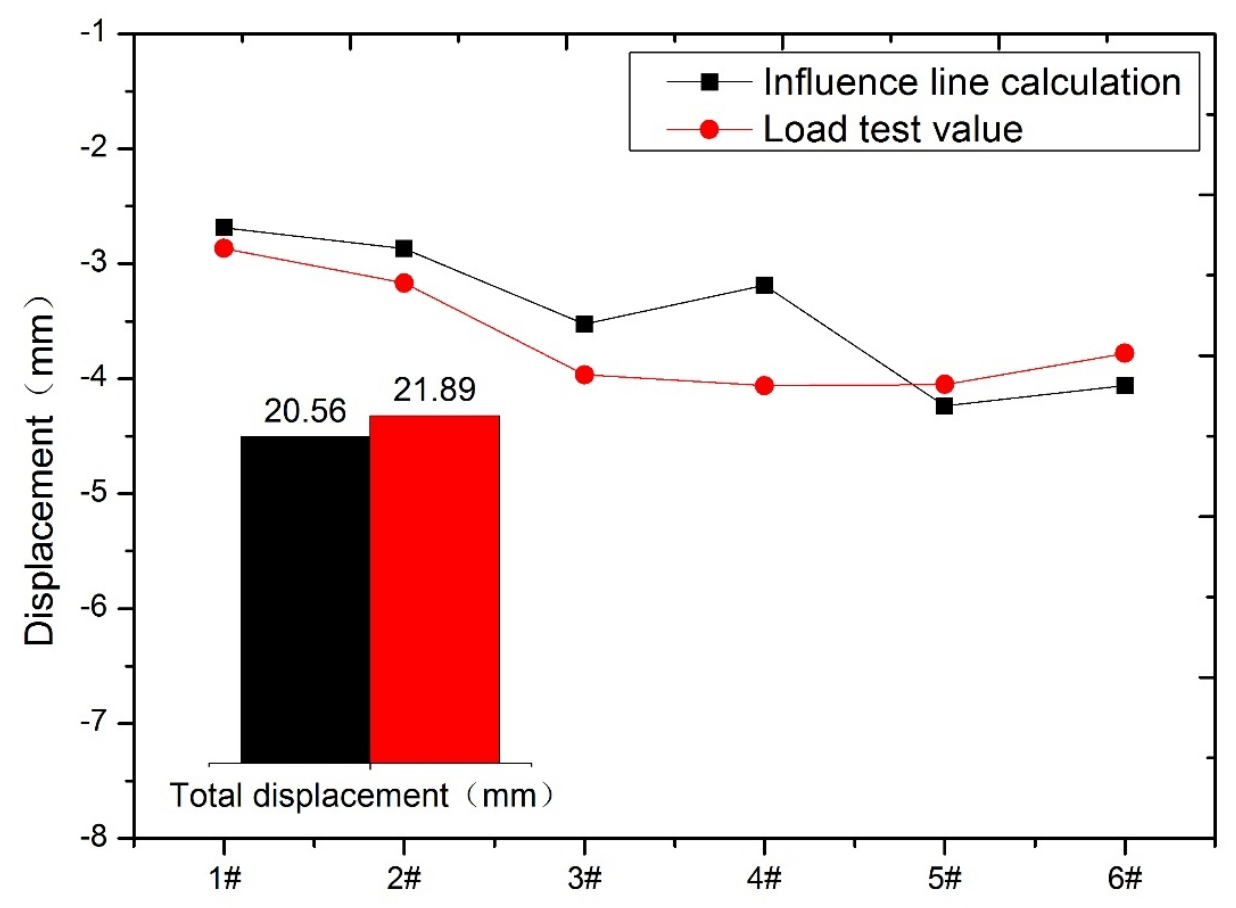

Fig3. Comparison of the displacement of each beam

From Figure 3, we can see that the two methods to get the displacement value is basically the same, the displacement of the beam total value respectively $-20.56 \mathrm{~mm}$ and $-21.89 \mathrm{~mm}$, about $6.08 \%$ the relative error between the two, indicating that ideal results can also be obtained by a combination of direct method of measured displacement influence line and can be used for assessment of the bridge. The table 3 shows, two methods to calculate the maximum calibration coefficient were 0.48 and 0.46 , according to "highway bridge carrying capacity evaluation procedures" (JTG / J21-2011), structural checking calculation coefficient $\mathrm{Z}_{2}$ are respectively 1.22 and 1.24 , little difference, can meet the bridge bearing capacity evaluation.

\section{Conclusion}

Through the above research, we can draw the following conclusions:

(1) According to the quasi static test to obtain the continuous displacement curve, the least square method can be used to obtain the displacement of the structure of the line, using the 4 polynomial fitting with high accuracy. 
(2) The calculated displacement values of the influence line are basically consistent with the measured values of the load test, and the difference is about $6 \%$. The results can be used to evaluate the bearing capacity of the bridge.

(3) According to the highway bridge carrying capacity evaluation procedures "(JTG / J21-2011) requirements of bridge load-bearing capacity evaluation, the displacement influence line determination coefficient $Z_{2}$ and checking calculation and precision can meet the needs assessment.

\section{Acknowledgements}

The paper is supported by the Henan Provincial Traffic Science Research Institute. In the process of writing, my leadership and colleagues in a number of professional issues to give me great help, expressed deep gratitude!

\section{References}

[1]Y. J. Wu, Y. F. Zhang and L. M. Zhang: Modern Transportation Technology, Vo. 3 (2012), p. 19; [2] Western China Communications Science \& Technology, Vo. 1 (2014), p. 1;

[3] G.W.Tang, J.B.Liao, Y.J.Zhang: Journal of Highway and Transportation Research and Development, Vo. 6 (2013), p. 42;

[4] Z. Zhao: Jinan University, (2014);

[5] Y.H.Zhao: Guangzhou University, (2015);

[6] L.B.Wang, D.L.Hu: Journal of Chang'an University(Natural Science Edition), Vo. 4 (2010), p. 51; (in Chinese)

[7]H.Y.Li: Chongqing Jiaotong University, (2009);

[8] J.T.Zhou, Y.Hao.X.J.Shen: Journal of Highway and Transportation Research and Development, Vo. 6 (2006), p. 81;

[9] P.D.Yu, L.Zhang, X.K.Li: World Bridges, Vo. 3 (2012), p. 59;

[10] N.B.Wang, W.X.Ren, L.X.He: Journal of Central South University(Science and Technology) , Vo. 12 (2014), p. 4362. 